\title{
AVALIAÇÃO DE FONTES DE CARBONO INDUTORAS DA SÍNTESE DE CELULASES POR UM Bacillus $s p$.
}

\author{
P. V. S. DIAS ${ }^{1}$, I. Q. de M. PADILHA ${ }^{2}$, D. A. M. de ARAÚJO², F. L. H. da SILVA ${ }^{1}$ e S. F. de M. \\ SANTOS $^{1}$ \\ ${ }^{1}$ Universidade Federal da Paraíba, Departamento de Engenharia Química \\ ${ }^{2}$ Universidade Federal da Paraíba, Departamento de Biotecnologia \\ E-mail para contato: sharlinefm@hotmail.com
}

\begin{abstract}
RESUMO - As celulases são enzimas altamente específicas, responsáveis pela hidrólise enzimática da celulose. A produção de celulases é induzida quando há a necessidade de serem secretadas pelos microrganismos para que estes cresçam em celulose. Este trabalho avaliou a indução da síntese de celulases por diferentes fortes de carbono pela linhagem de Bacillus sp. C1AC55.07, isolado do solo de uma indústria sucroalcooleira. As fontes de carbono utilizadas foram carboximetilcelulose (CMC), lactose, bagaço de cana sem prétratamento, bagaço de cana explodido, sabugo de milho e farelo de trigo. $\mathrm{O}$ cultivo foi realizado em meio líquido usando $1,0 \%$ da fonte de carbono, em erlenmeyer de $500 \mathrm{~mL}$ com $250 \mathrm{~mL}$ de meio, a $32{ }^{\circ} \mathrm{C}, 180 \mathrm{rpm}$ e $20 \%$ (v/v) de inóculo padronizado com Densidade Ótica (D.O.) de 1,1. A atividade enzimática de carboximetilcelulase (CMCase) foi medida a partir do sobrenadante obtido do cultivo após centrifugação das amostras retiradas a cada 6 h de cultivo. Para os cultivos com lactose e CMC, o crescimento celular foi medido por meio da análise de D.O. Entre os resultados obtidos, o maior pico de atividade observado foi de $0,263 \mathrm{U} / \mathrm{mL}$, com lactose como fonte de carbono, em $12 \mathrm{~h}$ de cultivo.
\end{abstract}

\section{INTRODUÇÃO}

Os materiais lignocelulósicos (materiais derivados de fibra vegetal) são a maior fonte renovável de material orgânico do mundo, e possuem grande potencial para a produção de bioenergia e subprodutos químicos (Rastogi et al., 2010). Nesse contexto, surge o conceito de biorrefinaria o qual, segundo Cherubini (2010), utiliza diferentes tecnologias capazes de separar as unidades que constituem as fontes de biomassa (como madeira, grãos e cana-de-açúcar), resultando em unidades menores, como carboidratos, os quais podem ser convertidos em produtos de alto valor agregado, como biodiesel, bioetanol de segunda geração, ácido lático e aminoácidos, sendo o bioetanol o de maior interesse por fazer parte da matriz energética mundial. Devido à grande variedade e ao gênero dos subprodutos que podem ser obtidos a partir da biorrefinaria, esta se apresenta como uma alternativa renovável à refinaria de petróleo.

No processo de biotransformação dos materiais lignocelulósicos em produtos de interesse, são utilizadas enzimas chamadas celulases, responsáveis por quebrar ligações glicosídicas que formam o 


\section{9 a 22 de outubro de 2014 \\ Florianópolis/SC}

principal biopolímero presente nesta matéria-prima (celulose), gerando moléculas de glicose (Gutiérrez-Rojas et al., 2014), das quais derivam grande parte dos produtos da biorrefinaria. Entretanto, os processos de obtenção dessas enzimas encarecem sua aplicação industrial (Narasimha et al., 2006).

Atualmente a maior fonte de celulases industriais são os fungos filamentosos (Valencia e Chambergo, 2013). Uma alternativa, visando o barateamento da obtenção dessas enzimas, é a utilização de bactérias para a produção de celulases, devido à rápida taxa de crescimento desses microrganismos associada à capacidade de muitas cepas de produzir complexos enzimáticos em sistemas aeróbios e anaeróbios (Amore et al., 2013), tornando as condições necessárias para a produção enzimática mais brandas, resultando no possível barateamento do processo.

Tendo em vista a diminuição dos custos de obtenção de celulases a fim de contribuir para a viabilização do conceito de biorrefinaria, este trabalho se propõe a avaliar a indução da produção de celulases por diferentes fortes de carbono em um Bacillus $s p$. isolado do solo de uma indústria sucroalcoleira localizada no interior da Paraíba. Dessa forma, foram utilizadas seis fontes de carbono: carboximetilcelulose, lactose, bagaço de cana-de-açúcar sem pré-tratamento, bagaço de cana-deaçúcar explodido, sabugo de milho e farelo de trigo.

\section{METODOLOGIA}

\subsection{Microrganismo}

A bactéria utilizada foi cedida pelo Prof. Dr. Demetrius Antônio Machado de Araújo do Centro de Biotecnologia-UFPB e foi isolada pelo aluno do Programa de Pós Graduação em Biotecnologia, (Renorbio) Itácio Queiroz de Melo Padilha. A cepa foi isolada do solo cultivado de cana-de-açúcar da Usina Japungu Agroindustrial S.A., localizada no interior da Paraíba, no município de Santa Rita, e selecionada para este trabalho por ser produtora de carboximetilcelulase.

\subsection{Avaliação das fontes de carbono indutoras}

Para a avaliação de indução da síntese de celulases pela cepa de Bacillus sp. C1AC55.07 por diferentes fontes de carbono, foi realizado um cultivo em meio líquido para cada fonte avaliada. Para tanto, o primeiro passo foi a preparação do pré-inóculo e do inóculo, com o objetivo de obter um inóculo do meio de produção caracterizado por uma elevada concentração celular. Em seguida, foi realizado o cultivo de produção, do qual foram recolhidas amostras periódicas para análise de crescimento celular e de atividade enzimática. Todos os cultivos de produção foram realizados em duplicata.

Pré-inóculo: O pré-inóculo foi inoculado a partir do estoque da cepa, armazenado em meio LB (Luria Bertani) sólido com $1 \%$ de $\mathrm{CMC}$, a $4^{\circ} \mathrm{C}$. O meio utilizado no pré-inóculo tem a seguinte composição: CMC (10 g/L), Extrato de Levedura $(2 \mathrm{~g} / \mathrm{L}) ; \mathrm{KH}_{2} \mathrm{PO}_{4}(1 \mathrm{~g} / \mathrm{L}) ; \mathrm{K}_{2} \mathrm{HPO}_{4}(1,145 \mathrm{~g} / \mathrm{L})$; $\mathrm{MgSO}_{4} .7 \mathrm{H}_{2} \mathrm{O}(0,4 \mathrm{~g} / \mathrm{L}) ; \mathrm{CaCl}_{2} \cdot 2 \mathrm{H}_{2} \mathrm{O}(0,05 \mathrm{~g} / \mathrm{L}) ; \mathrm{FeSO}_{4} .7 \mathrm{H}_{2} \mathrm{O}(0,00125 \mathrm{~g} / \mathrm{L}$ ) (Ariffin et al., 2008). $\mathrm{O}$ 


\section{9 a 22 de outubro de 2014 \\ Florianópolis/SC}

cultivo foi realizado em erlenmeyer de $125 \mathrm{~mL}$, contendo $50 \mathrm{~mL}$ de cultivo, em mesa agitadora, a 32 ${ }^{\circ} \mathrm{C}, 180 \mathrm{rpm}$, por $18 \mathrm{~h}$.

Inóculo: Para a inoculação do inóculo, foram transferidos $9 \mathrm{~mL}$ de pré-inóculo para o inóculo, cujo volume total foi de $450 \mathrm{~mL}$. O meio utilizado no inóculo é idêntico ao utilizado no pré-inóculo, e o cultivo foi realizado em erlenmeyer de $1000 \mathrm{~mL}$, em mesa agitadora, a $32^{\circ} \mathrm{C}, 180 \mathrm{rpm}$, por $20 \mathrm{~h}$. $\mathrm{O}$ inóculo foi padronizado através de sua densidade óptica a $600 \mathrm{~nm}$, definida como $1,1 \pm 1$.

Cultivo de produção: Cada cultivo de produção teve volume de $250 \mathrm{~mL}$, e foi cultivado em erlenmeyer de $500 \mathrm{~mL}$. O meio utilizado foi descrito por Ariffin et al. (2008), permutando apenas as fontes de carbono: Fonte de Carbono (10 g/L), Extrato de Levedura (2 g/L); $\mathrm{KH}_{2} \mathrm{PO}_{4}(1 \mathrm{~g} / \mathrm{L}) ; \mathrm{K}_{2} \mathrm{HPO}_{4}$ $(1,145 \mathrm{~g} / \mathrm{L}) ; \mathrm{MgSO}_{4} \cdot 7 \mathrm{H}_{2} \mathrm{O}(0,4 \mathrm{~g} / \mathrm{L}) ; \mathrm{CaCl}_{2} \cdot 2 \mathrm{H}_{2} \mathrm{O}(0,05 \mathrm{~g} / \mathrm{L}) ; \mathrm{FeSO}_{4} \cdot 7 \mathrm{H}_{2} \mathrm{O}(0,00125 \mathrm{~g} / \mathrm{L})$. As fontes de carbono utilizadas foram carboximetilcelulose, bagaço de cana-de-açúcar, bagaço de cana-deaçúcar explodido, lactose, sabugo de milho e farelo de trigo. $\mathrm{O}$ cultivo foi realizado com uma concentração inicial de $20 \%$ (v/v) de inóculo, em mesa agitadora, a $32{ }^{\circ} \mathrm{C}$ e $180 \mathrm{rpm}$. Amostras de 2 mL de todos os cultivos foram retiradas após 0 h, 6 h, 12 h, 24 h, 30 h, 36 h, 48 h, 54 h, 60 h e 72 h de cultivo para análise de atividade enzimática.

Curva de crescimento: Para analisar o crescimento celular, foi realizada uma curva de crescimento, que relaciona a absorbância óptica (D.O.) do cultivo a $600 \mathrm{~nm}$ e o tempo de cultivo, assumindo que aumento de concentração de células no meio de cultivo está diretamente relacionado com o aumento de turbidez do mesmo. Para tanto, as amostras retiradas foram diluídas em água destilada na proporção de 1:1, tento em vista que a elevada turvação do meio poderia assumir valores de absorbância altos o suficiente a ponto de afetar a precisão e a exatidão da medida. Este ensaio foi realizado apenas para os cultivos que utilizaram CMC e lactose como fontes de carbono, visto que as outras fontes de carbono não são solúveis, e representam um interferente na leitura da absorbância das amostras.

Curva de atividade enzimática: Para ensaio da atividade enzimática, as amostras recolhidas do cultivo foram centrifugadas a $4200 \mathrm{rpm}$, por $5 \mathrm{~min}$ a $25^{\circ} \mathrm{C}$. Apenas o sobrenadante foi utilizado para a execução do protocolo proposto por Ghose (1987) para a determinação da atividade enzimática. Esse protocolo é baseado na quantificação de glicose liberada quando o extrato enzimático é posto em contato com CMC, em um meio reacional com pH definido pela utilização de uma solução tampão. A incubação foi feita utilizando solução tampão fosfato, com pH 7, e a temperatura reacional foi de 50 ${ }^{\circ} \mathrm{C}$. O controle da amostra foi feito a partir de solução tampão com extrato enzimático, sem a adição de substrato (CMC), a fim de eliminar a influência de outros fatores que colaboram com a liberação da glicose na determinação da atividade enzimática. $O$ cálculo da atividade enzimática foi feito através da Equação 1.

$$
\operatorname{CMCase}(U / m L)=\frac{(A-B) \times f \times d \times 0,5}{0,18 \times 10 \times 0,25}
$$

Onde A é a absorbância da amostra, B é a absorbância do controle da amostra, f é o fator de conversão da curva de calibração que relaciona a concentração de glicose com a absorbância da 
amostra a $540 \mathrm{~nm}(\mathrm{mg} / \mathrm{mL})$, d é a diluição da amostra, 0,5 é o volume total de reação do meio $(\mathrm{mL})$, 0,18 é o fator de conversão de mg para $\mu$ mol de glicose, 10 é o tempo de reação (min) e 0,25 é o volume de extrato enzimático na reação $(\mathrm{mL})$.

Dessa forma, a curva de atividade enzimática foi construída relacionando os valores de atividade obtidos em cada tempo de cultivo, para cada fonte de carbono utilizada, gerando uma curva de atividade enzimática para cada fonte de carbono.

\section{RESULTADOS E DISCUSSÃO}

\subsection{Avaliação do crescimento em meios com lactose e CMC como fontes de carbono}

O crescimento da cepa C1AC55.07 nos meios contendo CMC e lactose apresentou comportamento semelhante em ambos os casos, como pode ser observado na Figura 1.

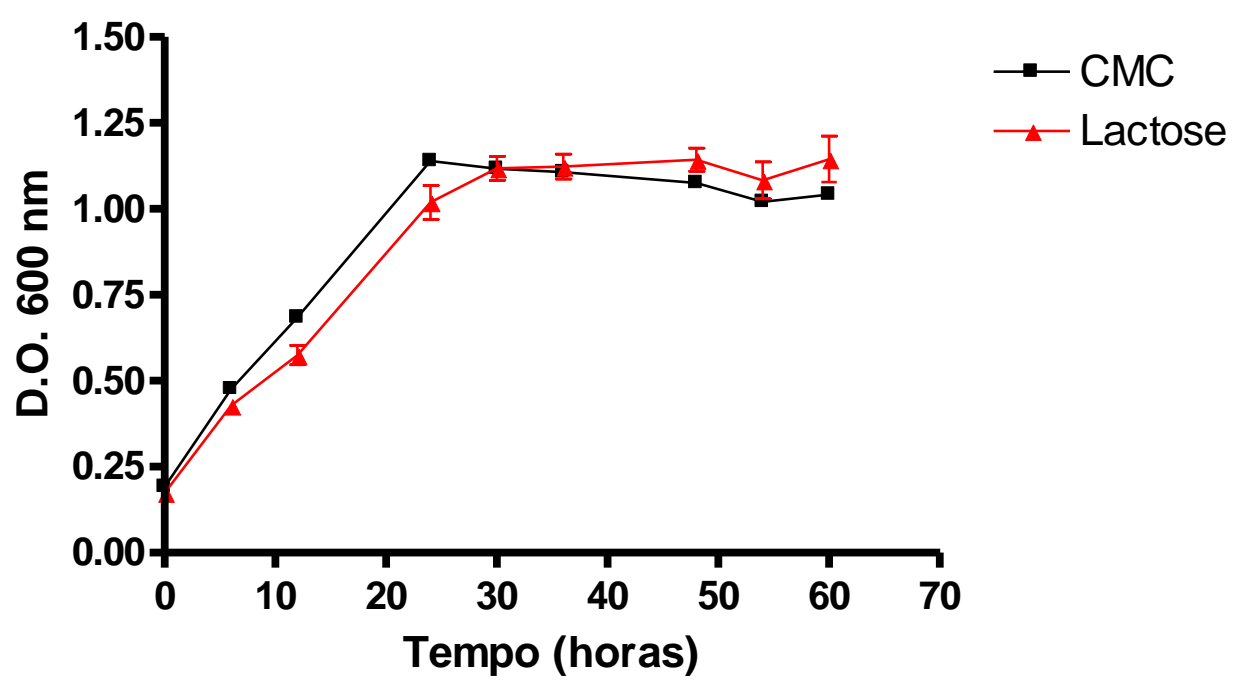

Figura 1 - Curva de crescimento da cepa C1AC55.07 em meio mínimo com fonte de carbono (घ) carboximetilcelulose e lactose $(\boldsymbol{\Delta})$.

As duas curvas de crescimento exibidas na Figura 1 mostram comportamento semelhante em relação às fases de crescimento microbiano, visto que, nos dois casos, pode-se observar duas fases bem definidas: a fase log, ou fase exponencial de crescimento, entre os tempos de $0 \mathrm{~h}$ e $24 \mathrm{~h}$ de cultivo, e a fase estacionária, fase onde a taxa de morte do microrganismo é igual à taxa de reprodução celular, de $24 \mathrm{~h}$ de cultivo em diante. De acordo com Tortora et al. (2005), na fase log, a 
reprodução celular é extremamente ativa, sendo a mesma o período de maior atividade metabólica do microrganismo, e, por consequência, o estágio preferido para fins industriais.

Outro fator que se apresenta semelhante nos meios de produção utilizando CMC e lactose como fonte de carbono é a concentração de células no meio, visto que a absorbância desses cultivos assumem valores muito próximos ao longo de todo o cultivo.

\subsection{Atividade Enzimática}

A cinética de produção enzimática dos seis cultivos da cepa C1AC55.07 utilizando diferentes fontes de carbono é mostrada na Figura 2. Observa-se que o pico de atividade é de 0,256 U/mL, quando a lactose é utilizada como fonte de carbono.
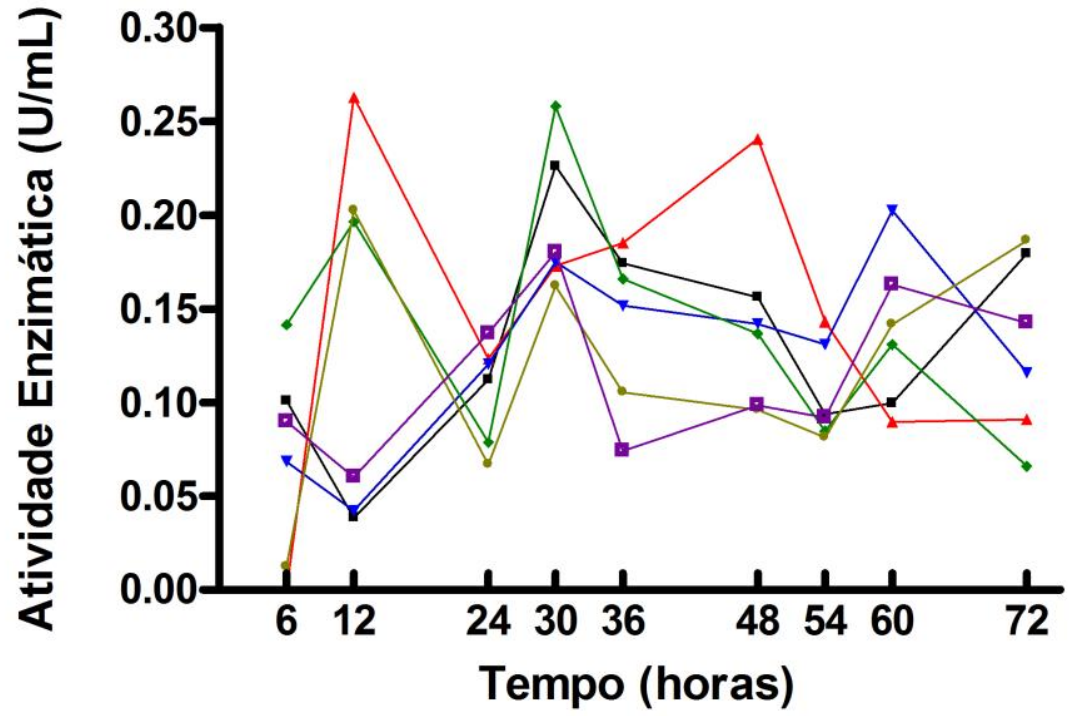

$\rightarrow \mathrm{CMC}$

$\longrightarrow$ Lactose

- Bagaço de Cana

- Bagaço Explodido

- Farelo de Trigo

$\rightarrow$ Sabugo de Milho

Figura 2 - Cinética enzimática obtida da cepa C1 AC55.07 cultivada em meio contendo CMC, Lactose, Bagaço de Cana-de-açúcar, Bagaço de Cana-de-açúcar Explodido, Sabugo de Milho ou Farelo de Trigo como Fonte de Carbono.

A Figura 2 também mostra a tendência de que as outras curvas de atividade assumam seu valor máximo em $30 \mathrm{~h}$ de cultivo, com exceção da curva de lactose, que assume o pico de atividade em 48 h de cultivo. Para uma análise mais criteriosa, a Figura 3 representa os valores máximos de produção enzimática da cepa C1AC55.07 quando cultivada com as seis fontes de carbono avaliadas. 


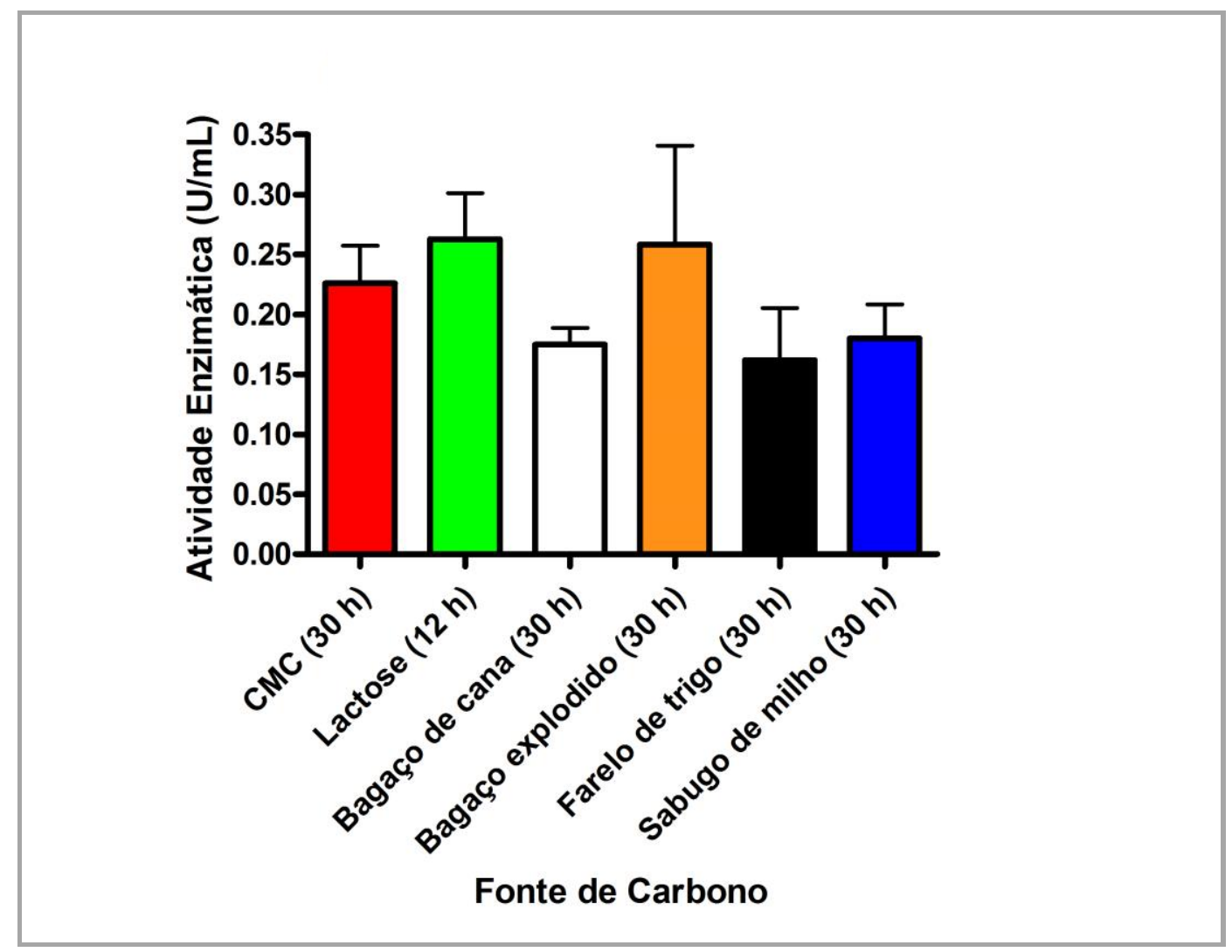

Figura 3 - Picos de produção de celulases pela cepa C1AC55.07 quando cultivada com CMC, Lactose, Bagaço de Cana-de-açúcar, Bagaço de Cana-de-açúcar Explodido, Farelo de Trigo ou Sabugo de Milho. O tempo de cultivo no qual foi obtido o pico de atividade para cada fonte de carbono está indicado em horas e a magnitude dos erros está representada acima das barras.

De acordo com a Figura 3, apesar de não haver diferença estatística pelo teste ANOVA, a lactose foi a fonte de carbono que mais induziu a produção de celulases na cepa C1AC55.07, atingindo um pico de atividade enzimática de $0,263 \mathrm{U} / \mathrm{mL}$, em $12 \mathrm{~h}$ de cultivo. $\mathrm{O}$ bagaço de cana explodido apresentou um valor de pico muito próximo do da lactose $(0,258 \mathrm{U} / \mathrm{mL})$ e maior que o valor observado para o bagaço de cana sem pré-tratamento. Um dos fatores que pode colaborar para a maior indução do Bagaço Explodido em relação ao bagaço bruto é o tratamento que este material sofre antes de ser submetido ao metabolismo microbiano, a Explosão de Vapor. Este pré tratamento consiste na exposição do Bagaço de Cana a vapor de água saturado a $160-240{ }^{\circ} \mathrm{C}$, o que envolve altas pressões. Como resultado, a hemicelulose e a lignina são parcialmente hidrolisadas, e a celulose, por consequência, tem seu grau de polimerização diminuído, enfraquecendo sua rede cristalina (Aguiar et al., 2013).

Ariffin et al. (2008) avaliaram a indução de três fontes de carbono na produção de celulases (óleo de palma pré-tratado, CMC solúvel e pó de $\mathrm{CMC}$ ) em um Bacillus pumilus, utilizando o mesmo meio de produção descrito neste trabalho, com uma concentração de inóculo de $10 \%(\mathrm{v} / \mathrm{v})$, a $37^{\circ} \mathrm{C} \mathrm{e}$ $200 \mathrm{rpm}$. O valor máximo de atividade enzimática obtido foi de $0,076 \mathrm{U} / \mathrm{mL}$, em $48 \mathrm{~h}$ de cultivo, 
quando o CMC solúvel foi utilizado como fonte de carbono. Neste trabalho, o CMC solúvel também foi utilizado, com uma concentração de inóculo de $20 \%$, a $32{ }^{\circ} \mathrm{C}$ e $180 \mathrm{rpm}$, com uma cepa de Bacillus sp., resultando em um pico de atividade enzimática de 0,226 U/mL, em $30 \mathrm{~h}$ de cultivo.

\section{CONCLUSÃO}

O presente trabalho avaliou a indução de diferentes fontes de carbono, a uma concentração fixa no meio de produção de $10 \mathrm{~g} / \mathrm{L}$, na produção de celulases pelo Bacillus sp. C1AC55.07. A lactose foi a fonte de carbono que mais induziu a produção de celulases na cepa C1AC55.07, sendo o pico de atividade enzimática de $0,263 \mathrm{U} / \mathrm{mL}$, em $12 \mathrm{~h}$ de cultivo. O próximo passo para a investigação da viabilidade econômica da utilização da lactose como fonte de carbono para a produção de celulases pela cepa C1AC55.07 é a avaliação da concentração ótima desta fonte de carbono.

\section{AGRADECIMENTOS}

Os autores agradecem ao Conselho Nacional de Desenvolvimento Científico e Tecnológico (CNPq), pelo apoio financeiro.

\section{REFERENCIAS}

AGUiAR, R. S.; SILVEIRA, M. H. L.; PITARELO, A. P.; CORAZZA, M. L.; Ramos, L. P. Kinetics of enzyme-catalyzed hydrolysis of steam-exploded sugarcane bagasse. Bioresour. Technol., v. 147, p. 416-423, 2013

AMORE, A.; PEPE, O.; VENTORINO, V.; BIROLO, L.; GIANGRANDE, C.; FARACO, V. Industrial waste based compost as a source of novel cellulolytic strains and enzymes. FEMS Microbiol. Let., v. 339(2), p. 93-101, 2013.

ARIFFIN, H.; HASSAN, M. A.; SHAH, U. K. M.; ABDULLAH, N.; GHAZALI, F. M.; SHIRAI, Y. Production of bacterial endoglucanase from pretreated oil palm empty fruit bunch by bacillus pumilus EB3. J. Biosci. Bioeng., v. 106(3), p. 231-236, 2008.

CHERUBINI, F. The biorefinery concept: using biomass instead of oil for producing energy and chemicals. Energ. Convers. Manage., v. 51, p. 1412-1421, 2010.

GHOSE, T.K. Measurement of cellulase activities. J. Macromol. Sci., Part A: Pure Appl. Che., v. 59, p. 257-268, 1987.

GUTIÉRREZ-ROJAS， I.; MORENO-SARMIENTO， N.; MONTOYA， D. Mecanismos y regulación de la hidrólisis enzimática de celulosa en hongos filamentosos: casos clásicos y nuevos modelos. Rev. Iberoam. Micol., 2014 
NARASIMHA, G.; SRIDEVI, A.; BUDDOLLA, V.; SUBHOSH, C. M.; RAJASEKHAR, R. B. Nutrient effects on production of cellulolytic enzymes by Aspergillus niger. Afr. J. Biotechnol., v. 5, p. 472-476, 2006.

RASTOGI, G., BHALlA, A., ADHIKARI, A., BISCHOFF, K. M., HUGHES, S. R., CHRISTOPHER, L. P., SANI, R. K. Characterization of thermostable cellulases produced by Bacillus and Geobacillus strains. Bioresour. Technol., v. 101, p. 8798-8806, 2010.

TORTORA, G. J.; FUNKE, B.R.; CASE, C. L. Microbiologia. Porto Alegre: Editora Artmed, 2005.

VALENCIA, E. Y.; CHAMBERGO, F. S. Mini-review: Brazilian fungi diversity for biomass degradation. Fungal Genet. Biol., v. 60, p. 9-18, 2013. 